Elsevier required licence: (c) <2018>. This manuscript version is made available under the CC-BY-NC-ND 4.0 license http://creativecommons.org/licenses/by-nc-nd/4.0/

The definitive publisher version is available online at https://doi.org/10.1016/j.jenvman.2018.03.002 


\title{
Computing the effective diffusion coefficient of solutes in a multi-salts solutions during forward osmosis (FO) membrane filtration: Experiments and mathematical modelling
}

S. Liyanaarachchi ${ }^{\mathrm{a}}$, S. Muthukumaran ${ }^{\text {b,c }}$, Joshua Kaiser ${ }^{\mathrm{d}}$, Paul Rogers ${ }^{\mathrm{d}}$, Li Shu ${ }^{\mathrm{e}}$, Ho Kyong Shon ${ }^{\mathrm{f}}$ and V. Jegatheesan ${ }^{\mathrm{a}}$

${ }^{\text {a }}$ School of Engineering, RMIT University, Melbourne, VIC 3000, Australia

${ }^{\mathrm{b}}$ College of Engineering and Science, Victoria University, PO Box 14428, Melbourne, VIC 8001, Australia

${ }^{\mathrm{c}}$ Institute for Sustainability and Innovation, Victoria University, PO Box 14428, Melbourne, VIC 8001, Australia

${ }^{\mathrm{d}}$ School of Engineering, Deakin University, Waurn Ponds, VIC 3216, Australia

${ }^{\text {e}}$ LJS Environment, Parkville, VIC 3052, Australia

fSchool of Civil and Environmental Engineering, University of Technology, Sydney, Post Box 129, Broadway, NSW 2007, Australia.

"Corresponding author: Jega Jegatheesan (jega.jegathesan@ @rmit.edu.au, +61 39925 0810)

\begin{abstract}
Diffusion coefficient of solutes through a porous membrane media is different from diffusion coefficient through a free homogenous media. Porosity, tortuosity and the thickness of the membrane significantly affect the diffusion through a specific thickness of a membrane and therefore it is termed as effective diffusion coefficient $\left(D_{\text {eff }}\right)$ which is lower than the actual diffusion coefficient, $\mathrm{D}$. The $\mathrm{D}_{\text {eff }}$ of single or dual solutes through a porous membrane layer are well documented but not for multiple salts. Therefore, in this study, single, dual and multiple salt mixtures were passed through a flat sheet cellulose triacetate Forward Osmosis
\end{abstract}


(FO) membrane to obtain a semi-empirical relationship with the $\mathrm{D}_{\text {eff }}$ and its water flux. This

will allow computing the structural coefficient of FO membranes. Research community have spent tremendous efforts in membrane modification to reduce the structural coefficient to improve FO process efficiency. Our finding suggests that optimising the draw solution chemistry can achieve this goal.

Keywords: Effective diffusion; Forward osmosis; Concentration polarization; Reverse osmosis; Seawater

\section{Introduction}

Forward osmosis (FO) is a novel emerging membrane process which can be used to concentrate a dilute aqueous stream through the use of a concentrated stream obtained from another process such as reverse osmosis (RO). When those two liquid streams are separated by an FO membrane, the osmotic pressure difference between two liquids will allow water to diffuse through the membrane from the diluted stream to the concentrated stream (Cath et al., 2006). However, the amount of water diffused depends on the orientation of the membrane. When the active and the support layers of the membrane face the diluted (or feed) stream and the concentrated (or draw) stream respectively, the mode of the orientation is called AL-FS (active layer facing feed stream). When it is the other way around, the configuration is called to be in AL-DS (active layer facing draw stream) mode. In addition to the desired water flux, there is an undesirable solute diffusion (known as reverse salt flux - RSF) due to the concentration gradient between feed and draw solution will also occur which would lower the performance of the membrane process significantly (Touati and Tadeo, 2006; Ray et al., 2018).

Diffusion is the dominant solute transport mechanism through a porous membrane layer of nano-filtration as well as reverse and forward osmosis membranes. Therefore, to understand the solute transport through a porous FO membrane material, the diffusion coefficient $(D)$ of solutes were experimentally determined. However, when the solutes transport through a tortuous path, effective diffusion coefficient, $D_{e f f}$, is always less than the theoretical $D$, which is given by Fick's Law. The value of $D_{\text {eff }}$ (equation (1)) of a solute depends on the tortuous path it travels and therefore depends on the porosity $(\epsilon)$ and tortuosity $(\tau)$ as well as the thickness of the membrane $(t)$. 
$D_{\text {eff }}=\frac{t \tau}{\epsilon K}$

Where, parameter $K$ defines the solute resistivity for diffusion within the porous support layer of the membrane. The value of $K$ is a measure of how easily a solute can diffuse through the support layer and thus is a measure of the severity of internal concentration polarisation (ICP) (McCutcheon et al., 2006; McCutcheon and Elimelech, 2006). The more severe the ICP, the lower the water flux through FO membrane. Therefore, it is important to study how $\mathrm{K}$ varies with different solutes. Depending on the mode of the orientation of the membrane, K will be denoted either as $K_{D}$ (AL-DS mode) or $K_{F}$ (AL-FS mode). Figure 1 shows the internal and external concentration polarisation during forward osmosis under AL-DS mode. When the FO process is carried out, water will move from the feed solution to the draw solution through the FO membrane. The solutes present in the bulk feed solution will be transported to the membrane surface that is exposed to the feed solution. Thus the concentration on the membrane surface will be higher than the concentration in the bulk feed solution which will create a concentrative external concentration polarisation as shown in Figure 1. In AL-DS mode, the concentration of those solutes (present in the feed solution) will continue increase thorough the porous support layer and will create a concentrative internal concentration polarisation on the interface between the porous support layer and the active layer (that is exposed to the draw solution in the AL-DS mode). On the other hand, the concentration of solutes present in the bulk draw solution will decrease near the membrane surface that is exposed to the draw solution due to the dilution caused by the water flux from the feed solution. This will cause a dilutive external concentration polarisation on the draw solution side of the membrane as shown in Figure 1. The effective osmotic pressure difference across the active layer of the membrane will depend on the osmotic pressure differences caused by the dilutive external concentration polarisation and the concentrative internal concentration polarisation as shown in Figure 1.

Figure 1

The literature has well explained theories to predict the effective diffusion coefficient, $D_{e f f}$, in the presence of a single salt (Cath et al., 2006; Tan and Ng, 2008; Leob et al., 1997). When multiple salts are present, the effective diffusivity is completely different due to mutual diffusion, ionic size, charge of the solute and properties of the porous media (Miller et al., 2007; Mathew et al., 1989; Holloway et al., 2015). As per the literature survey, there are no studies on predicting the $D_{e f f}$ of multiple salt solutions. Therefore, this study is carried out to 
evaluate the value of $D_{e f f}$ in the presence of multiple solutes. The $D_{e f f}$ will be calculated for different selected salt mixtures, with the help of experimental and theoretical data. A semiempirical relationship of $D_{e f f}$ with water flux will be obtained. The solute resistivity, $K$, and the structural constant, $K D_{\text {eff }}$, for each selected salt will be described.

\section{Materials and methods}

\subsection{Model development}

The literature has well documented procedures on how to model the flux through the FO membrane (Tan and Ng, 2008; Lee et al., 1981; Tang et al., 2010). Mathematical models proposed by various researchers consider the solute flux through the membrane in order to compute the effective osmotic pressure which is the driving factor in the FO process (McCutcheon and Elimelech, 2006). Models for predicting the water flux across an asymmetric FO membrane have been developed to take into account both external and internal concentration polarization (CP) effects. The following equations were obtained based on the literature (Cath et al., 2006; McCutcheon et al.,2006; McCutcheon and Elimelech, 2006; Tan and Ng, 2008; Leob et al., 1997; Gray et al., 2006) where the flux across the membrane will depend on the surface area of the membrane and the osmotic pressure difference between the membrane interface (between the active and support layers) and the membrane surface of the active layer facing the feed or draw stream (the membrane surface of the active layer will face either the feed or draw stream depending on the mode of the orientation of the membrane).

For AL-FS mode:

The water flux, $J_{w}$ is given by equation (2):

$J_{w}=A \sigma\left(\pi_{F, i}-\pi_{F, m}\right)$

Where, $A$ is the permeability coefficient, $\sigma$ is the reflection coefficient, $\pi_{F, i}$ (equation (3)) and $\pi_{F, m}$ (equation (4)) are osmotic pressures at the membrane interface (between the active and support layers) and the membrane surface that is facing the feed stream, respectively; $\pi_{F, i}$ can be related to the osmotic pressure of the bulk draw solution, $\pi_{D, b}$ as below:

$\pi_{F, i}=\pi_{D, b} \exp \left(-J_{w} K_{D}\right)$

Where, $K_{D}$ is the solute resistivity. Similarly, $\pi_{F, m}$ can be related to the osmotic pressure of the bulk feed solution, $\pi_{F, b}$ as below:

$\pi_{F, m}=\pi_{F, b} \exp \left(-\frac{J_{w}}{k_{f}}\right)$ 
Where, $k_{f}$ is the mass transfer coefficient of solute from the bulk feed stream to the surface of the membrane. Thus, equation (2) can be rearranged to an expression shown in equation (5):

$J_{w}=A \sigma\left[\pi_{D, b} \exp \left(-J_{w} K_{D}\right)-\pi_{F, b} \exp \left(-\frac{J_{w}}{k_{f}}\right)\right]$

Similarly, for AL-DS mode, $J_{w}$ can be given by equation (6):

$J_{w}=A \sigma\left[\pi_{D, b} \exp \left(-\frac{J_{w}}{k_{d}}\right)-\pi_{F, b} \exp \left(-J_{w} K_{F}\right)\right]$

Where, $k_{d}$ is the mass transfer coefficient of solute from the membrane to the bulk draw stream. $K_{D}$ and $K_{F}$ are solute resistivity values for AL-DS and AL-FS modes, respectively, and can be obtained from the following equations (7) and (8):

$$
\begin{aligned}
& K_{D}=\left(\frac{1}{J_{w}}\right) \ln \left\lfloor\frac{B+A \pi_{D, b}}{B+J_{w}+A \pi_{F, m}}\right\rfloor \\
& K_{F}=\left(\frac{1}{J_{w}}\right) \ln \left\lfloor\frac{B+A \pi_{D, b}-J_{w}}{B+J_{w}+A \pi_{F, m}}\right\rfloor
\end{aligned}
$$

Where, $\mathrm{B}$ is the salt permeability coefficient. When de-ionized water and brine solutions are used as feed and draw solutions, respectively, equations (5) and (6) can be simplified to the following forms as shown in equation (9) and (10):

$$
\begin{array}{ll}
\text { AL-FS mode: } & J_{w}=A \pi_{D, b} \exp \left(-J_{w} K_{D}\right) \\
\text { AL-DS mode: } & J_{w}=A \pi_{D, b} \exp \left(-J_{w} / k_{d}\right)
\end{array}
$$

While equation (10) will allow computing the mass transfer coefficient $k_{d}$ using the experimental flux, equation (9) can be used to compute the solute resistivity, $K_{D}$. By using $k_{d}$, the effective diffusion coefficient, $D_{e f f}$ of solutes present in the brine solution can be estimated using equation (11):

$D_{e f f}=\frac{k_{d} d_{h}}{1.85\left(\operatorname{Re} * S c * \frac{d h}{L}\right)^{0.33}}$

Where, $d_{h}$ is the hydraulic diameter of the feed channel (to the membrane), $R e$ is the Reynolds number of the flow, $S c$ is the Schmidt number and $L$ is the length of the channel. Equation (11) is valid when the flow through the feed channel is laminar $\left(\operatorname{Re}<2 \times 10^{5}\right)$ where the Sherwood number, $S h$ can be given by equation (12):

$S h=\left(\operatorname{Re} * S c * \frac{d h}{L}\right)^{0.33}$

Similarly, computing $K_{D} D_{\text {eff }}$ can be used to find the structural constant of the FO membrane using equation (1). In this approach, values of solute rejection, $R$, and the salt permeability 
coefficient, B, are not required to compute $K_{D}$ and $D_{\text {eff }}$. The structural constant can also be defined as give in equation (13):

$K_{D} D_{e f f}=t \tau / \varepsilon$

Where, $t, \tau$ and $\varepsilon$ are the thickness, tortuosity and porosity of the FO membrane. Thus, smaller the structural constant the larger the flux will be. Research community have spent tremendous efforts in membrane modification to reduce the structural coefficient to improve FO process efficiency. As can be seen from in subsequent sections, our finding suggests that optimising the draw solution chemistry can achieve this goal.

\subsection{Preparation of draw solution and chemical analysis}

Seawater collected from Geelong, Australia, was pre-filtered to remove large suspended particles such as seaweeds. Optimum $\mathrm{FeCl}_{3}$ coagulant dose $(5 \mathrm{mg} / \mathrm{L}$, which was obtained from jar tests) was added to seawater and was passed through a cylindrical dual media filter (DMF) at a rate of $7.6 \mathrm{~m} / \mathrm{h}$ where DMF diameter, sand media bed depth and anthracite media bed depth were 50, 400 and $300 \mathrm{~mm}$, respectively. After $4 \mathrm{~h}$ of filtration, filter media bed was backwashed for 2 min using tap water. The $\mathrm{pH}$, total organic carbon (TOC), electrical conductivity (EC) and turbidity of the seawater and filtered seawater were determined. Part of the filtered seawater was used as draw solution, at different dilutions, in subsequent FO experiments. Rest of the filtered seawater was passed through spiral wound RO membrane (SG1812C-28D from General Electric Company; $\mathrm{NaCl}$ rejection $=97 \%$ and area $=0.27 \mathrm{~m}^{2}$ ) and the concentrate obtained from this process was used at different dilutions in subsequent experiments. The properties of seawater, filtered seawater and RO concentrate are given in Table 1(a).

The composition of anions and cations present in the filtered seawater and reverse osmosis concentrate are given in Table 1(b). Cations were identified using Atomic Absorption Spectrometry (AAS) and anion concentrations were measured using Merk® test kits.

Table 1(a)

Table 1(b) 
Additionally, de-ionized water as feed solution and $\mathrm{K}_{2} \mathrm{SO}_{4}, \mathrm{Na}_{2} \mathrm{SO}_{4}, \mathrm{NaCl}, \mathrm{MgCl}_{2}, \mathrm{~K}_{2} \mathrm{SO}_{4}+$ $\mathrm{MgCl}_{2}+\mathrm{Na}_{2} \mathrm{SO}_{4}, \mathrm{~K}_{2} \mathrm{SO}_{4}+\mathrm{MgCl}_{2}, \mathrm{~K}_{2} \mathrm{SO}_{4}+\mathrm{Na}_{2} \mathrm{SO}_{4}, \mathrm{MgCl}_{2}+\mathrm{Na}_{2} \mathrm{SO}_{4}$ as draw solutions were also prepared. Final concentrations of all the single, dual and triple salt solutions were fixed at $30 \mathrm{~g} / \mathrm{L}$ which was in the range of seawater salinity. Mixed salt concentrations, according to the equivalent molar ratio of each salt, are given in Table 2. Further, as mentioned above, RO concentrate (brine) and filtered seawater solutions were diluted to 25, 50, 75 and $100 \%$ using de-ionized water in order to have a range of salt concentrations. Here $25 \%$ dilution means $100 \mathrm{~L}$ of either filtered seawater or RO concentrate is diluted by adding $25 \mathrm{~L}$ of de-ionised water.

Table 2

\subsection{Experimental setup}

Figure 2 shows the experimental setup used in this study. Flat sheet CTA, FO membranes with a woven, embedded support backing and average pore diameter of $0.74 \mathrm{~nm}$ (Xie et al., 2012) were purchased from Hydration Technologies Inc (HTI), USA.

Figure 2

\subsection{Experimental procedure}

Prior to the FO experiments, the $\mathrm{pH}$, temperature and electrical conductivity (EC) of feed and the draw solutions were measured. Feed and draw solutions were passed through the membrane at ambient temperature $\left(20^{\circ} \mathrm{C}\right)$ at a rate of $0.50 \mathrm{~m} / \mathrm{s}$ cross flow velocity in counter current flow configuration. Change in the weight of the draw solution was programmed to be stored in a data logger at one minute time intervals which allowed to compute experimental water flux $\left(J_{w, e}\right)$. During one hour of membrane filtration, properties of the feed and draw solutions $(\mathrm{pH}$, EC and temperature) were measured at every 10 minutes. Experiments were run in both ALDS and AL-FS modes to aid structural parameter calculations. A new membrane coupon was used for each salt solution. All the experiments were duplicated. Density, viscosity and osmotic pressure of each salt solution and salt mixture were obtained using the OLI@ stream analyzer and reported in Table 3. With the help of experimental and theoretical data, effective diffusion coefficients of draw solutions were calculated. 
Table 3

\subsection{Method to predict effective diffusion coefficient}

Equations (9) and (10) are used to calculate solute resistivity and mass transfer coefficient using the flux values obtained when the FO membrane is operated in AL-FS and AL-DS modes, respectively. Mass transfer coefficient can then be used to compute the effective diffusion coefficient from which the structural constant can be calculated.

\section{Results and discussion}

\subsection{FO experimental results}

Concentration polarisation (CP) effects on the draw solution sides are dilutive external concentration polarization (DECP) (in AL-DS mode) and combined DECP and dilutive internal concentration polarization (DICP) (in AL-FS mode). Since de-ionized water was used as feed, concentrative external concentration polarization (CECP) and concentrative internal concentration polarization (CICP) effects on the feed solution sides were minimized (or negligible) in these experiments.

Experimental water flux in each mode was calculated and is shown in Figure 3. the value 1 on the $\mathrm{x}$-axes indicates that there is no dilution was made to the original solution and the concentrations of salts are the actual concentrations present in the original solution. As the dilution increases, the relative concentration of salts decreases. The adjusted $R^{2}$ and the standard error (SE) values for the correlation between the flux and dilution for seawater under AL-FS and AL-DS modes are $0.97\left(=\mathrm{R}^{2}\right), 0.11(=\mathrm{SE})$ and 0.88 and 0.76 respectively. Very high adjusted $\mathrm{R}^{2}$ and low standard error indicate that the relationship between the flux and the dilution are well correlated. Similarly, the adjusted $\mathrm{R}^{2}$ and the standard error for the correlation between the flux and dilution for RO brine under AL-FS and AL-DS modes are 0.94, 0.23 and 0.977 and 0.45 respectively, which are again indicating that the relationship between the flux and the dilution are well correlated for the experiments conducted with RO brine. Further, the low $\mathrm{p}$ values (which are having the values 0.001 and 0.012 for seawater under AL-FS and ALDS modes, respectively and 0.004 and 0.001 for RO brine under AL-FS and AL-DS modes, respectively and therefore less than 0.05 under all the experimental conditions) indicate that the dilution effect is significant on the magnitude of the flux produce by FO process. Higher 
water flux was observed under AL-DS mode compared to AL-FS mode, as expected (Zhao et al., 2011), for all 3 types of draw solutions. Zhao et al. (2011) reported that membrane orientation is basically influenced by the feed solution composition and the degree of concentration (i.e., concentration factor or water recovery). Further, AL-DS mode is preferable when using the solutions with low salinity feed. Since the feed solution is DI water in this study, AL-DS mode showed better performance with regards to the water flux.

Figure 3

Further, in AL-FS mode, ICP is severe as all the draw solutes are passing through porous side of the membrane. This gives a lower water flux in AL-FS mode compared to AL-DS. The rate of increase in water flux when brine and seawater concentration increase, is lower in AL-FS mode. This is evidenced as the increase in water flux (gradient) with the increase in draw solution concentration at AL-FS and AL-DS modes are 4.71 and 14.92, respectively for RO brine and 3.27 and 10.54 for Seawater, respectively. Overall, AL-FS mode gradient is one third of the gradient for the AL-DS mode. Even though a correlation cannot be obtained for single, dual and triple salt solutions, similar to the previous two types of draw solutions, ALDS mode flux is higher compared to AL-FS mode. The mixture of several salts present in the draw solution gave higher flux compared to the presence of single salt in the draw solution.

\subsection{Prediction of effective diffusion coefficient}

Solute resistivity and mass transfer coefficient were calculated using the flux values obtained when the FO membrane is operated in AL-FS and AL-DS modes, respectively. Mass transfer coefficient was then used to compute the effective diffusion coefficient which was then used to compute the structural constant. Table 4 gives those values under every experimental condition.

Table 4

Calculated $D_{e f f}$ values were plotted for each salt solution and given in Figure 4 . The $D_{\text {eff }}$ for single, dual and triple salt solutions is significantly lower compared to those for seawater and 
brine solutions. The $0 \%, 25 \%, 50 \%$ diluted brine showed $D_{\text {eff }}$ values up to $4.5 \times 10^{-6} \mathrm{~cm}^{2} / \mathrm{s}$ and $0 \%, 25 \%$ diluted seawater showed up to $3 \times 10^{-6} \mathrm{~cm}^{2} / \mathrm{s}$.

Figure 4

Irrespective of the combinations of salts, a relationship of $D_{e f f}$ with water flux was developed. Change in water flux is plotted against the effective diffusion coefficient in AL-FS and AL-DS modes (Figure 5). At higher effective diffusion coefficient values, a higher water flux was observed in both modes. The correlation of water flux and $D_{e f f}$ is given by the two trend lines displayed in Figure 5.

Figure 5(a) shows the AL-FS mode results. The logarithmic semi-empirical relationship of water flux $\left(J_{w}\right)$ and effective diffusion coefficient $\left(D_{e f f}\right)$, displayed using dotted line, has the coefficient of determination, $\mathrm{R}^{2}$ of 0.7753 and is given in equation (14) below.

$J_{w}=1.995 \ln \left(D_{\text {eff }}\right)+31.72$

The adjusted $\mathrm{R}^{2}$, SE and $\mathrm{p}$ are $0.76,0.83$ and $1.43 \times 10^{-6}$, respectively which indicate the correlation given in equation (14) is strong and the effective diffusion coefficient plays a significant role in the flux produced by the FO process. As the semi-empirical relationship predicts, at lower $D_{\text {eff }}$ values lower fluxes could be observed. However, when $D_{e f f}$ is higher, the rate of increase in water flux is low. This could be due to higher reverse salt flux as $D_{e f f}$ is higher.

Figure 5(b) shows the AL-DS mode results and its semi-empirical relationship is given in equation (12). AL-DS mode shows a better fit in logarithmic mode compared to AL-FS mode with a $\mathrm{R}^{2}$ value of 0.8843 . The adjusted $\mathrm{R}^{2}, \mathrm{SE}$ and $\mathrm{p}$ are $0.877,1.06$ and $6.66 \times 10^{-9}$, respectively which indicate the correlation given in equation (15) is strong and the effective diffusion coefficient plays a significant role in the flux produced by the FO process. However, similar to AL-FS mode, as $D_{\text {eff }}$ gets higher, increase in rate of water flux becomes lower.

$J_{w}=3.784 \ln \left(D_{\text {eff }}\right)+58.67$ 
Figure 5

Semi-empirically obtained solute resistivity values were plotted and given in Figure 6. $\mathrm{SO}_{4}{ }^{2-}$ solutions (either single or dual) show higher solute resistivity than $\mathrm{Cl}^{-}$solutions. This higher resistivity would have reduced the ICP effect and therefore higher water flux can be obtained. However, in this study the mass concentrations of the draw solutions were kept constant. Therefore, the osmotic pressures of draw solutions used were different. Due to the variation in osmotic pressures of draw solutions, the ICP effect of different draw solutions could only be inferred and cannot be identified from the results. A separate study with draw solutions that are having similar osmotic pressure can be carried out to evaluate this clearly.

Figure 6

However, blending $\mathrm{SO}_{4}{ }^{2-}$ with $\mathrm{Cl}^{-}$reduced the solute resistivity. Ionic size of $\mathrm{SO}_{4}{ }^{2-}$ and $\mathrm{Cl}^{-}$are 0.149 and $0.181 \mathrm{~nm}$, respectively. Since lower ionic sizes provide higher water and salt flux (Touati and Tadeo, 2016) $\mathrm{SO}_{4}{ }^{2-}$ should have shown better performance than $\mathrm{Cl}^{-}$. However, the hydrated ionic radius of $\mathrm{SO}_{4}{ }^{2-}(=0.30 \mathrm{~nm})$ is larger than the hydrated ionic radius $\mathrm{of}^{-} \mathrm{Cl}^{-}(=$ $0.27 \mathrm{~nm}$ ) and therefore, as shown in Figure 4, the water flux increases when higher $\mathrm{Cl}^{-}$ions are blended with $\mathrm{SO}_{4}{ }^{2-}$ ions. A study by Chekli et al.(2017) on evaluating fertilizer-drawn forward osmosis for sustainable agriculture and water reuse in arid regions also found that ionic species such as $\mathrm{K}^{+}, \mathrm{Cl}^{-}$and $\mathrm{NO}_{3}{ }^{-}$with small hydrated diameter presented in fertiliser solutions diffused through the membrane faster compared to ionic species such as $\mathrm{SO}_{4}{ }^{2-}$ and $\mathrm{PO}_{4}{ }^{3-}$ which are larger-sized hydrated anions. The experimental observations can be support from the dependence of diffusion of solutes on their molecular weights as well. It has been found that internal concentration polarisation (ICP) effects are severe when large molecular weight solutes are used in the draw solution. This is evident from a study conducted by Gray et al. (2006) where the sodium chloride (molecular weight of $58 \mathrm{~g} / \mathrm{mole}$ ) generated more flux than the dextrose (molecular weight of $180 \mathrm{~g} /$ mole) draw solution which in turn generated greater flux than the sucrose (molecular weight of $342 \mathrm{~g} /$ mole) draw solution at the same bulk osmotic pressure differential between the draw and the feed solutions. This occurs as the larger molecular weight solutes cannot diffuse as quickly as lower molecular weight solutes through the porous support layer, thus resulting in severe ICP effects and lower water flux through the membrane. This is applicable when $\mathrm{Cl}^{-}$(molecular weight of $35.5 \mathrm{~g}$ ) and $\mathrm{SO}_{4}{ }^{2-}$ (molecular 
weight of $96 \mathrm{~g}$ ) solutes are present in the draw solution. Draw solutions having $\mathrm{Cl}^{-}$will tend to give more flux compared to draw solutions having $\mathrm{SO}_{4}{ }^{2-}$ ions at same bulk osmotic pressure differential.

The structural coefficient of the FO membrane $K_{D} D_{\text {eff }}(=t \tau / \varepsilon)$ can vary with the concentration of the solutes as $\tau$ and $\varepsilon$ can be altered according to those concentrations. The porosity and the tortuosity can be varied with filtration time depending on the sizes of the solute ions. Therefore, we cannot expect the structural coefficient to be constant for any salt solution. As Figure 7 shows, the higher number of salts as well as higher concentrations ( $0 \%$ and $25 \%$ diluted brine) showed the highest $K_{D} D_{\text {eff }}$ values ( $\left.>2 \times 10^{-4} \mathrm{~m}\right)$ compared to other salt solutions. Further, $0 \%$ diluted seawater also has a higher $K_{D} D_{e f f}$ value, i.e., $1.92 \times 10^{-4} \mathrm{~m}$. the single, dual and triple salt solutions show comparatively lower structural coefficients.

\section{Figure 7}

The following will be the practical applications of this work: (i) when a mixture of salt solutions emanating from various sources such as landfill leachate, discharge from mine tailing ponds, effluents from industries such as dairy, chemical processing, pharmaceutical etc. is used in forward osmosis processes, by conducting a small number of experiments proposed in this study will assist in deriving the effective diffusion coefficients of those solution. This will help to predict the flux in the forward osmosis process under various operating conditions, (ii) interference of an anion on another anion's solute resistivity can be estimated and (iii) effect of solution chemistry of above mentioned liquid streams on the structural coefficient of a FO membrane can be explored.

The results of this study can direct researchers to following future research prospects: (i) studying the effect of various mixed salts having same osmotic pressure, (ii) establishing quantitative relationships on interference of an anion on another anion's solute resistivity, and (iii) characterising the performance of different FO membranes with respect to the flux it could produce when using various liquid streams mentioned in the above paragraph using their effective diffusion coefficient values. 


\section{Conclusions}

A semi empirical relationship to predict the effective diffusion coefficient, $\mathrm{D}_{\text {eff }}$ of solutes present in seawater and RO brine at different dilutions as well as synthetic single or multiple salt mixtures with same mass concentrations $(30 \mathrm{~g} / \mathrm{L})$ was studied in this work. Larger the concentrations of solutes either in seawater or RO brine, the higher the $\mathrm{D}_{\text {eff. For single and }}$ multiple salt solutions, the solute resistivity of $\mathrm{SO}_{4}{ }^{2-}$ ions was lowered when they were blended with $\mathrm{Cl}^{-}$ions which have lower molecular weight and lower hydrated ionic radius compared to $\mathrm{SO}_{4}{ }^{2-}$ ions. $\mathrm{As} \mathrm{Cl}^{-}$ions can diffuse faster and therefore increase the water flux in the FO process. Also, the structural coefficient, $\mathrm{K}_{\mathrm{D}} \mathrm{D}_{\text {eff }}$, varies depending on the type of the salt and its concentration implying that the combined membrane property term denoted by porosity, tortuosity and thickness $(t \tau / \varepsilon)$ is not a constant and could vary depending on the solution chemistry.

\section{References}

Cath, T.Y., Childress, A.E., Elimelech, M., 2006. Forward osmosis: Principles, applications, and recent developments. J. Membr. Sci. 281(1-2), 70-87.

Chekli, L., Kim, Y., Phuntsho, S., Li, S., Ghaffour, N., Leiknes, T.O., Shon, H.K., 2017. Evaluation of fertilizer-drawn forward osmosis for sustainable agriculture and water reuse in arid regions, J. Environ. Manag. 187, 137-145.

Gray, G.T., McCutcheon, J.R., Elimelech, M., 2006. Internal concentration polarization in forward osmosis: role of membrane orientation. Desalination, 197(1-3), 1-8.

Holloway, R.W., Maltos, R., Vanneste, J., Cath, T.Y., 2015. Mixed draw solutions for improved forward osmosis performance. J. Membr. Sci. 491, 121-131.

Lee, K.L., Baker, R.W., Lonsdale, H.K., 1981. Membranes for power generation by pressureretarded osmosis. J. Membr. Sci. 8(2), 141-171.

Loeb, S., Titelman, L., Korngold, E., Freiman, J., 1997. Effect of porous support fabric on osmosis through a Loeb-Sourirajan type asymmetric membrane. J. Membr. Sci. 129(2), 243249.

Mathew, R., Paduano, L., Albright, J.G., Miller, D.G., Rard, J.A., 1989. Isothermal Diffusion Coefficients for $\mathrm{NaCl}-\mathrm{MgCl}_{2}-\mathrm{H}_{2} \mathrm{O}$ at $25^{\circ} \mathrm{C}$. 3. Low $\mathrm{MgCl}_{2}$ concentrations with a Wide Range of $\mathrm{NaCl}$ Concentrations. J . Phys. Chem. 93, 4370-4374.

McCutcheon, J.R., McGinnis, R.L., M. Elimelech, 2006. Desalination by ammonia-carbon dioxide forward osmosis: Influence of draw and feed solution concentrations on process performance. J. Membr. Sci. 278(1-2), 114-123. 
McCutcheon, J.R., Elimelech, M. 2006. Influence of concentrative and dilutive internal concentration polarization on flux behavior in forward osmosis. J. Membr. Sci. 284(1-2), 237247.

Miller, D.G., Lee, C.M., Rard, J.A. 2007. Ternary isothermal diffusion coefficients of NaCl$\mathrm{MgCl}_{2}-\mathrm{H}_{2} \mathrm{O}$ at $25^{\circ} \mathrm{C}$. 7. Seawater composition. J Solution Chem. 36(11), 1559-1567.

Ray, S.S., Chen, S.S., Nguyen, N. C., Nguyen, H.T., Dan, N.P., Thanh, B.X., Trang, T., 2018. Exploration of polyelectrolyte incorporated with Triton-X 114 surfactant based osmotic agent for forward osmosis desalination. J. Environ. Manag. 209, 346-353.

Tan, C.H., Ng, H.Y., 2008. Modified models to predict flux behavior in forward osmosis in consideration of external and internal concentration polarizations. J. Membr. Sci. 324(1-2), 209-219.

Tang, C.Y., She, Q., Lay, W.C.L., Wang, R., Fane, A.G., 2010. Coupled effects of internal concentration polarization and fouling on flux behavior of forward osmosis membranes during humic acid filtration. J. Membr. Sci. 354(1-2), 123-133.

Touati, K., Tadeo, F., 2016. Study of the reverse salt diffusion in pressure retarded osmosis: Influence on concentration polarization and effect of the operating conditions. Desalination, $389,171-186$.

Xie, M., Nghiem, L.D., Price, W.E., Elimelech, M., 2012. Comparison of the removal of hydrophobic trace organic contaminants by forward osmosis and reverse osmosis. Water Res. 46(8), 2683-2692.

Zhao, S., Zou, L., Mulcahy, D., 2011. Effects of membrane orientation on process performance in forward osmosis applications. J. Membr. Sci. 382(1-2), 308-315. 


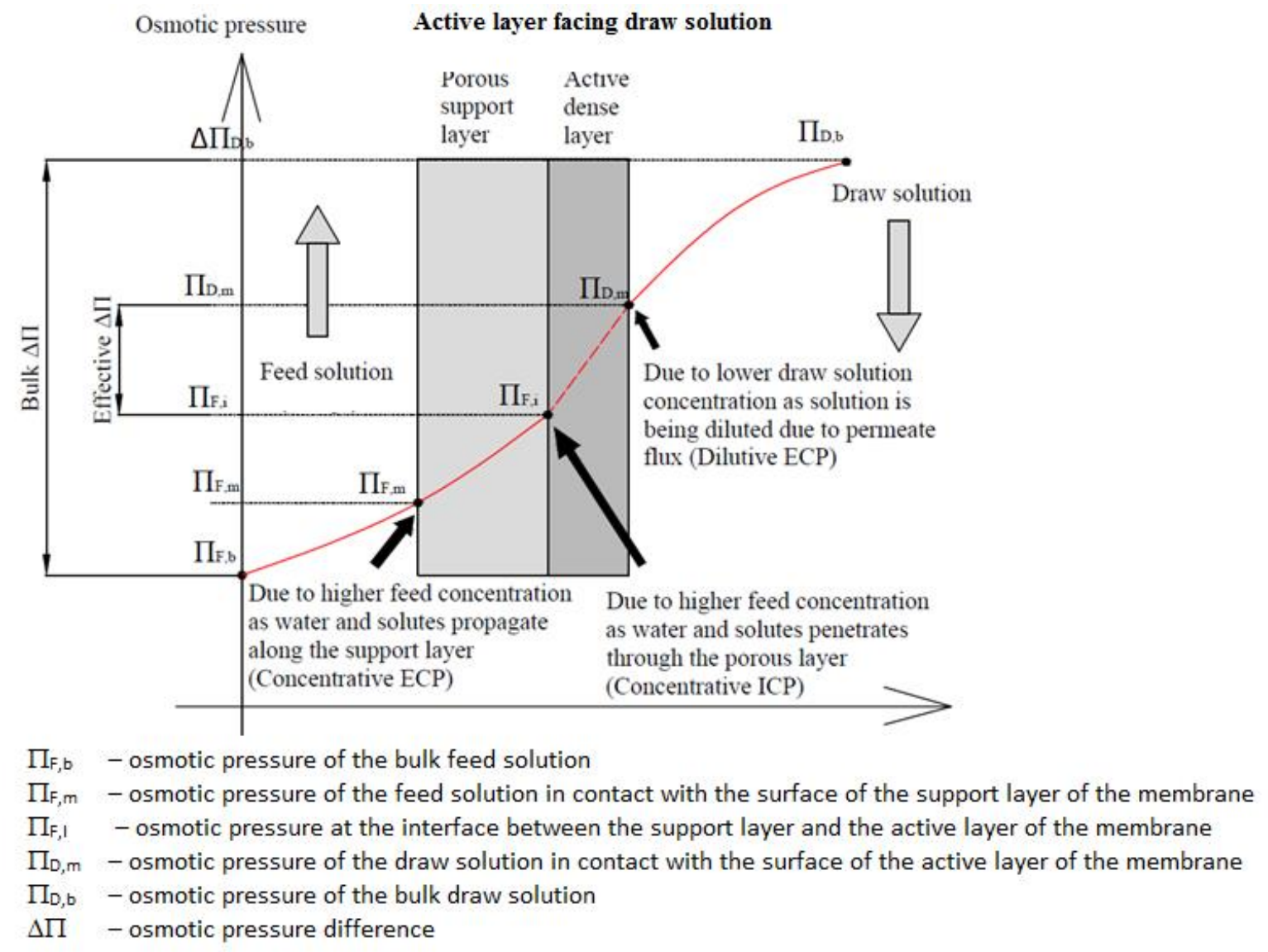

Figure 1 Factors affecting the flux through forward osmosis membrane when active layer is facing the draw solution 


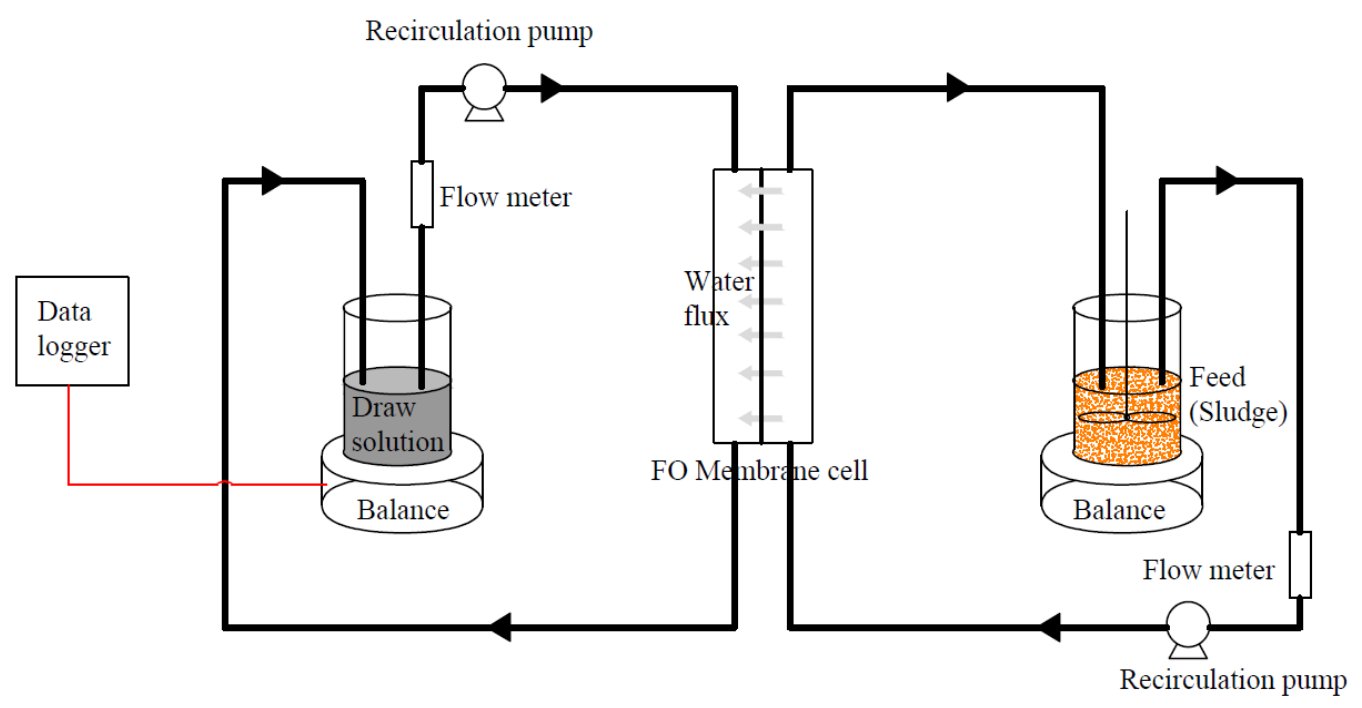

Figure 2 Schematic diagram of the FO set up used in this study

(Flat sheet FO module with a membrane area of $33.54 \mathrm{~cm}^{2}$ ) 
a)

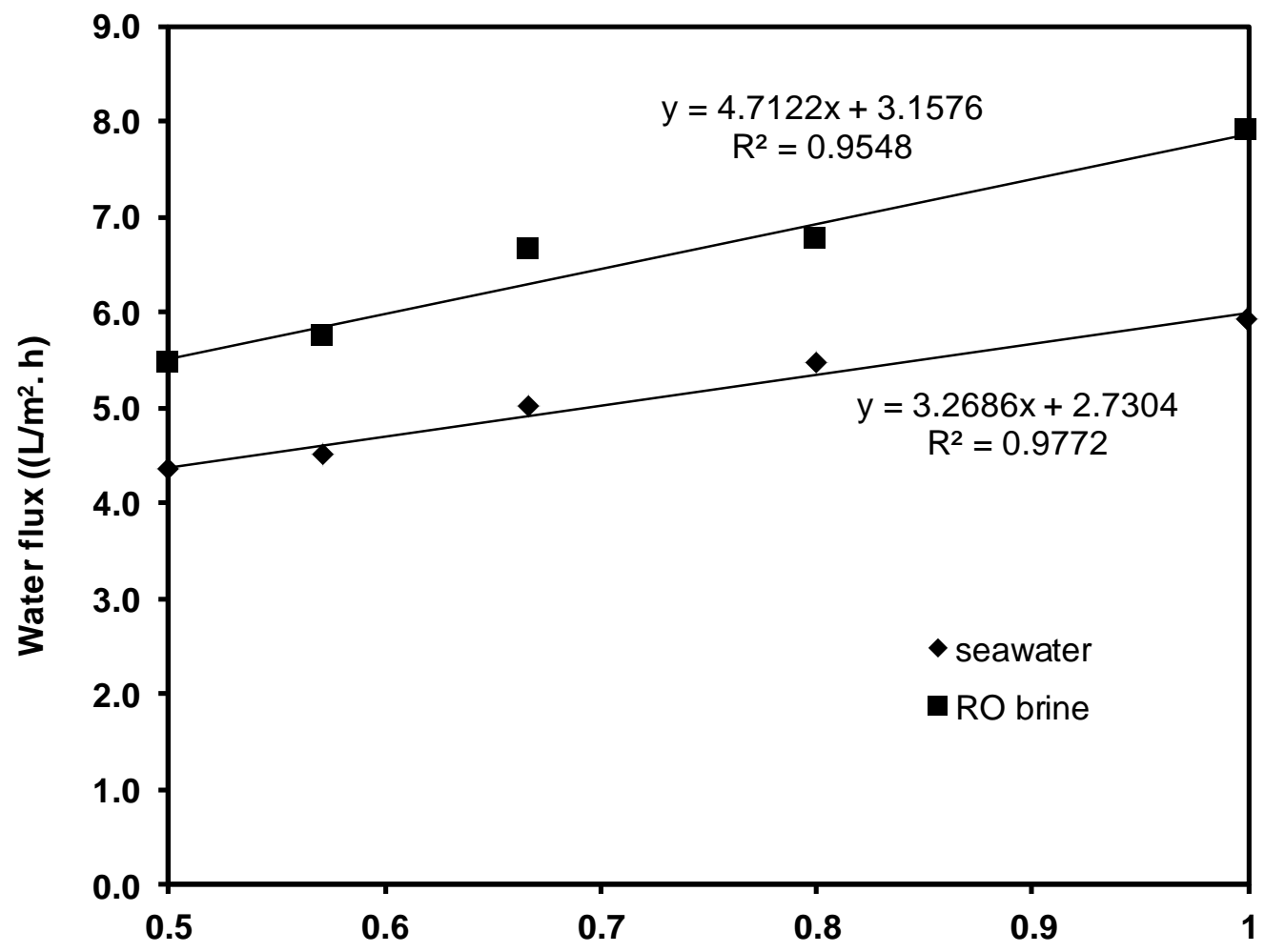

Relative concentration of salts due to dilution 
b)

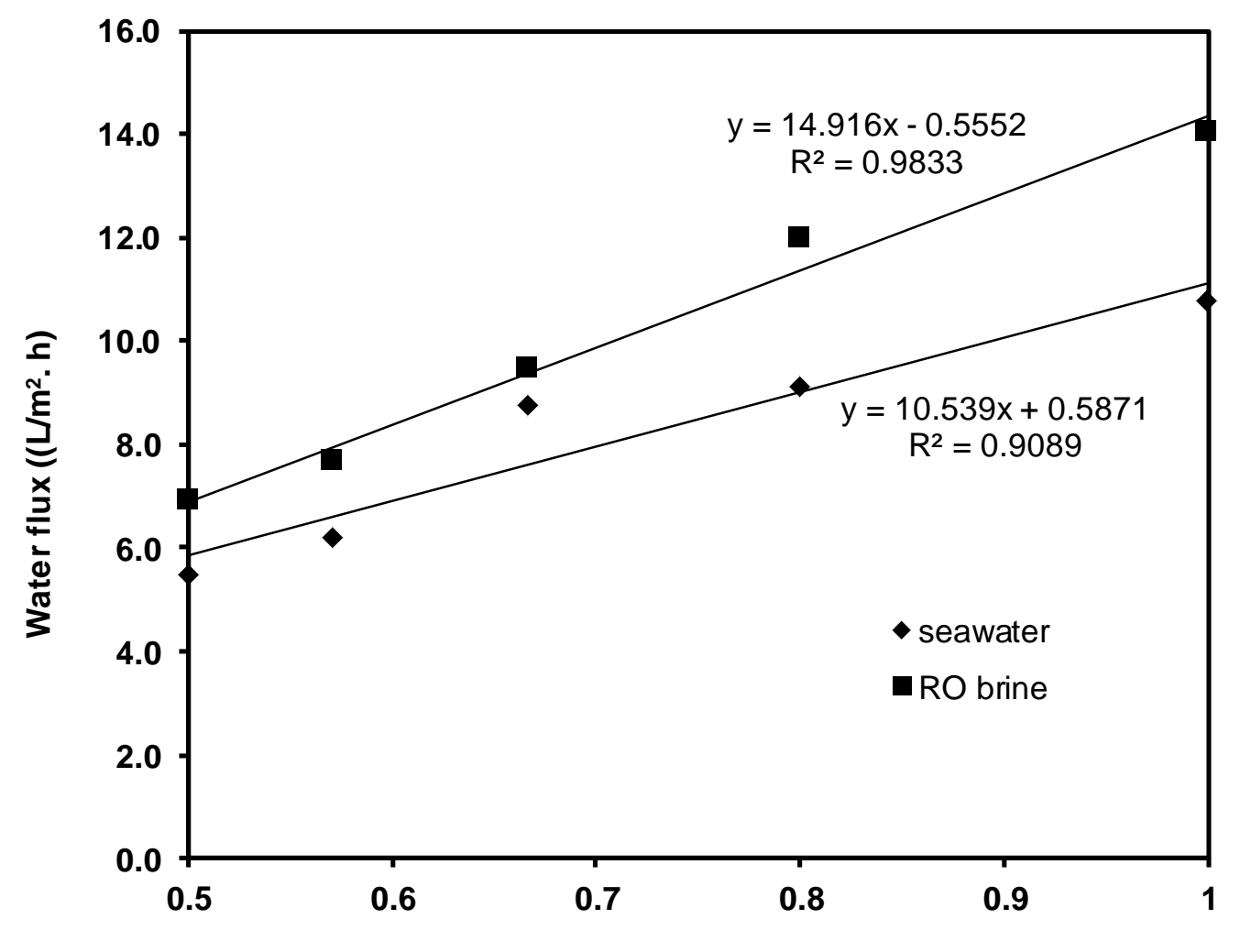

Re lative concentration of salts due to dilution 
c)

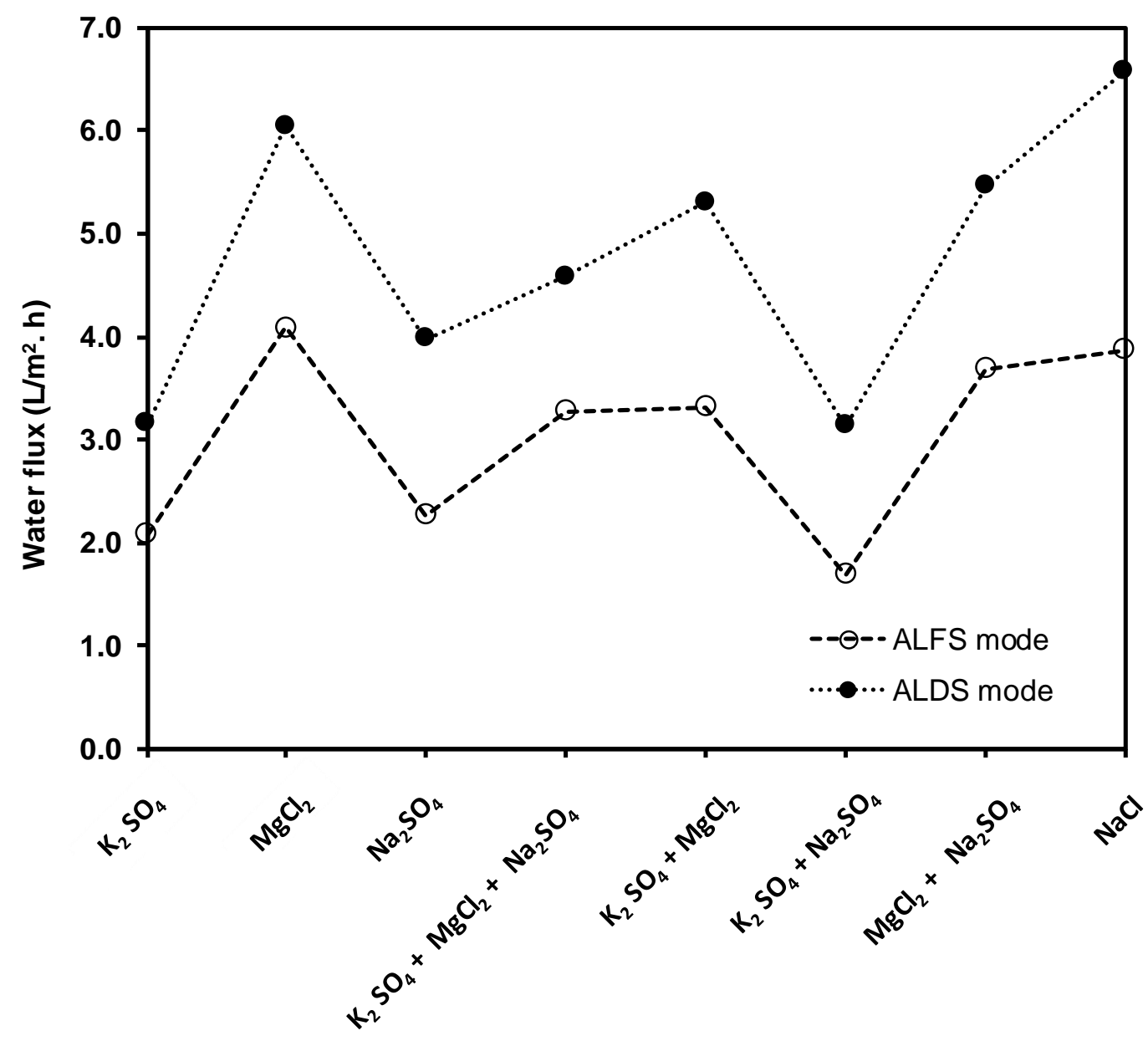

8 Figure 3 Water flux obtained for sea water and RO brine at different dilutions when a) active layer facing feed solution mode and b) active layer facing draw solution mode, configurations (the value 1 on the $\mathrm{x}$-axes indicates that there is no dilution was made to the original solution and the concentrations of salts are the actual concentrations present in the original solution); c) water flux of single and multiple salt solutions that are having same mass concentrations 


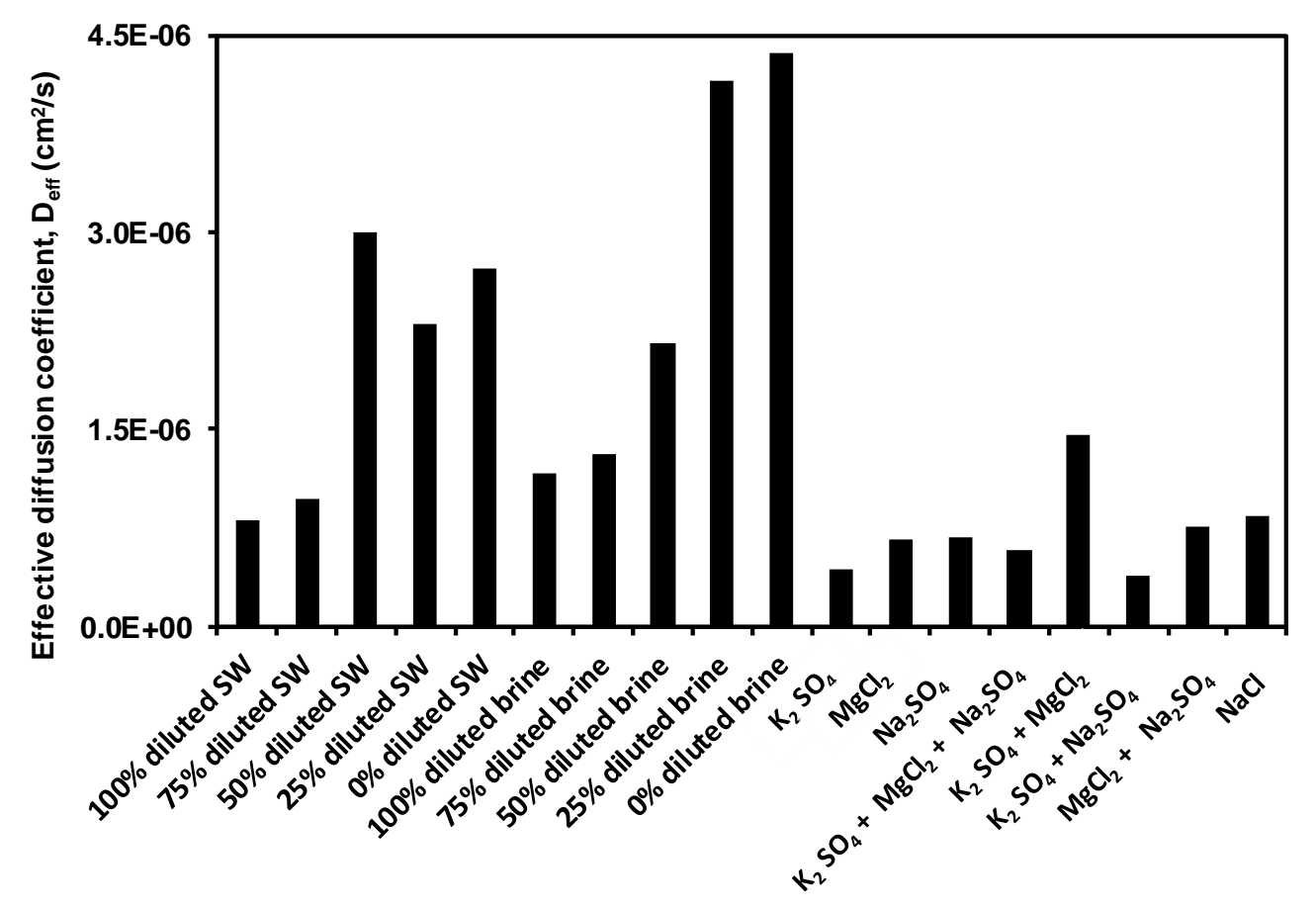

17

Figure $4 \quad$ Effect of salt on the effective diffusion coefficient, $D_{\text {eff }}$

(19)

0

(1)

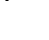




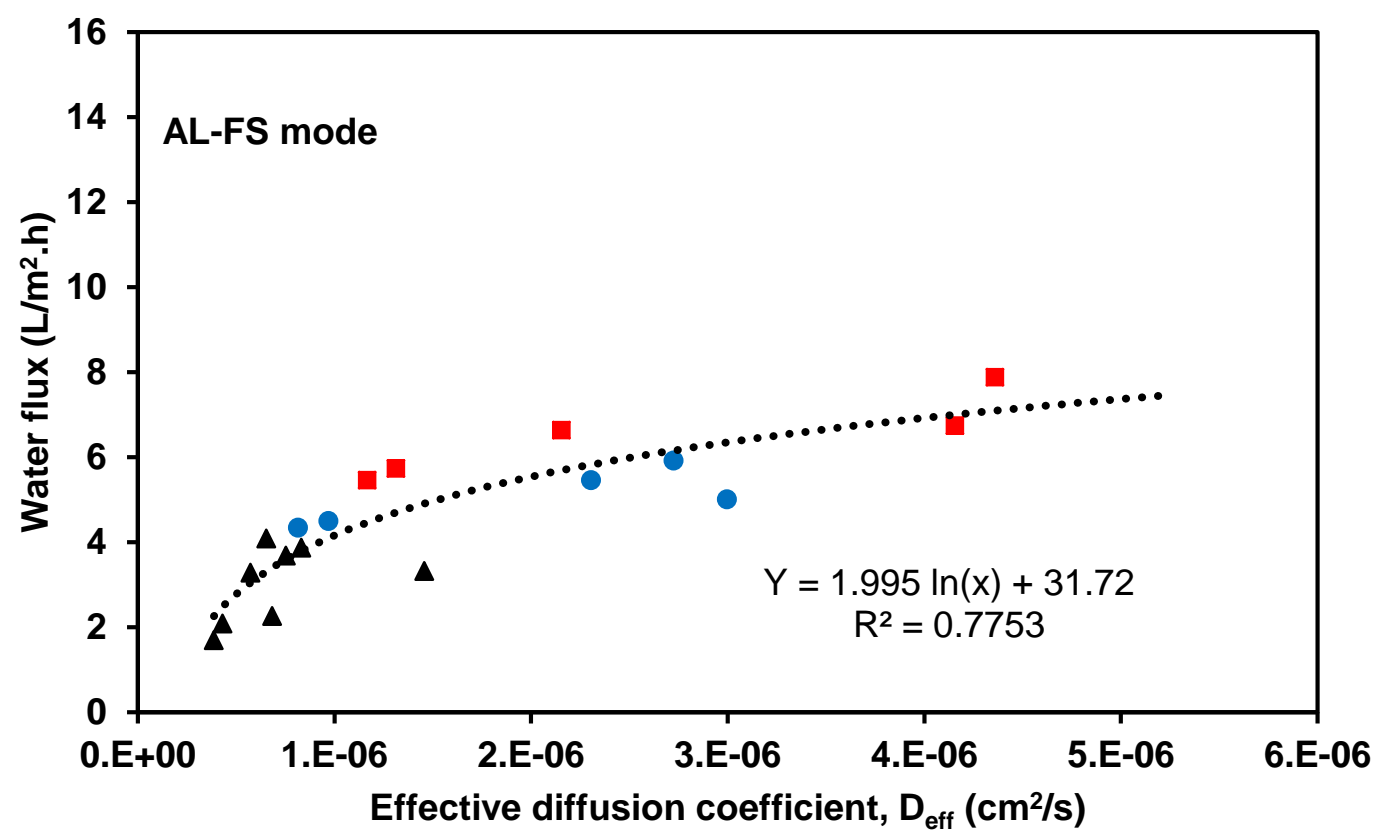

$40 \quad$ (b)

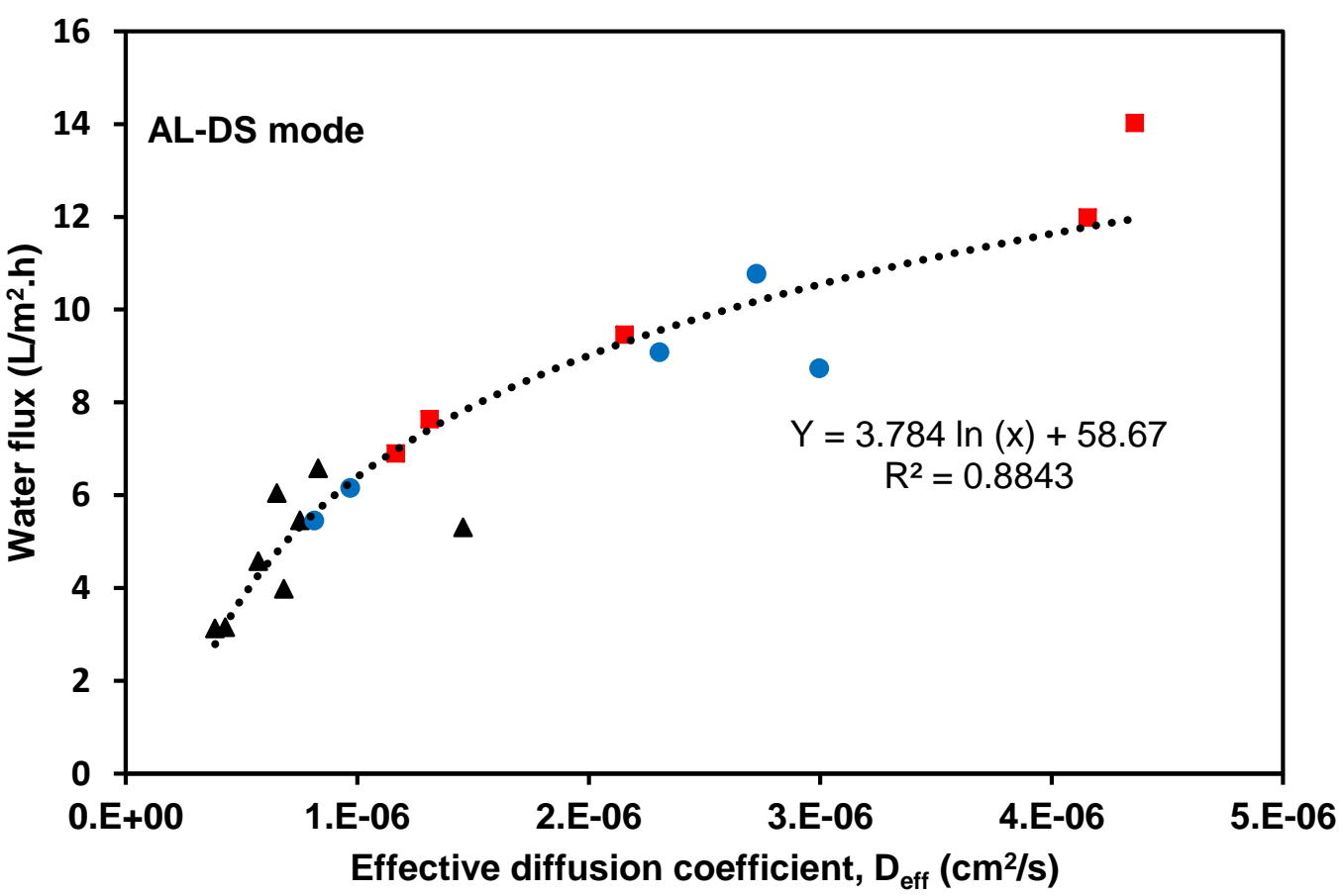

b)
42 Figure 5 Correlation of (a) active layer facing feed solution mode configuration and (b) active layer facing draw solution mode configuration water flux and effective diffusion coefficient. $\boldsymbol{\Delta}$ - salt solution $\boldsymbol{\square}$ - RO brine and •- seawater


a)

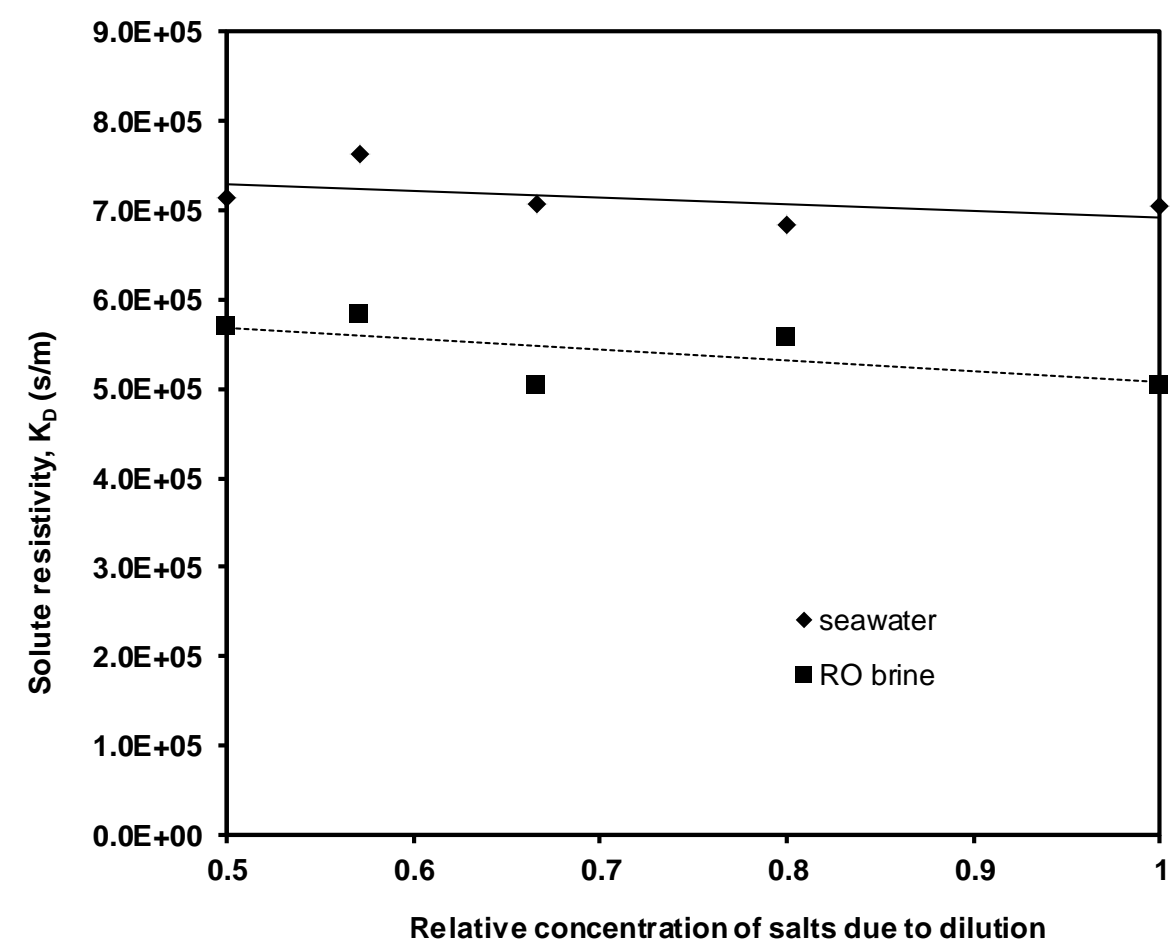

b)

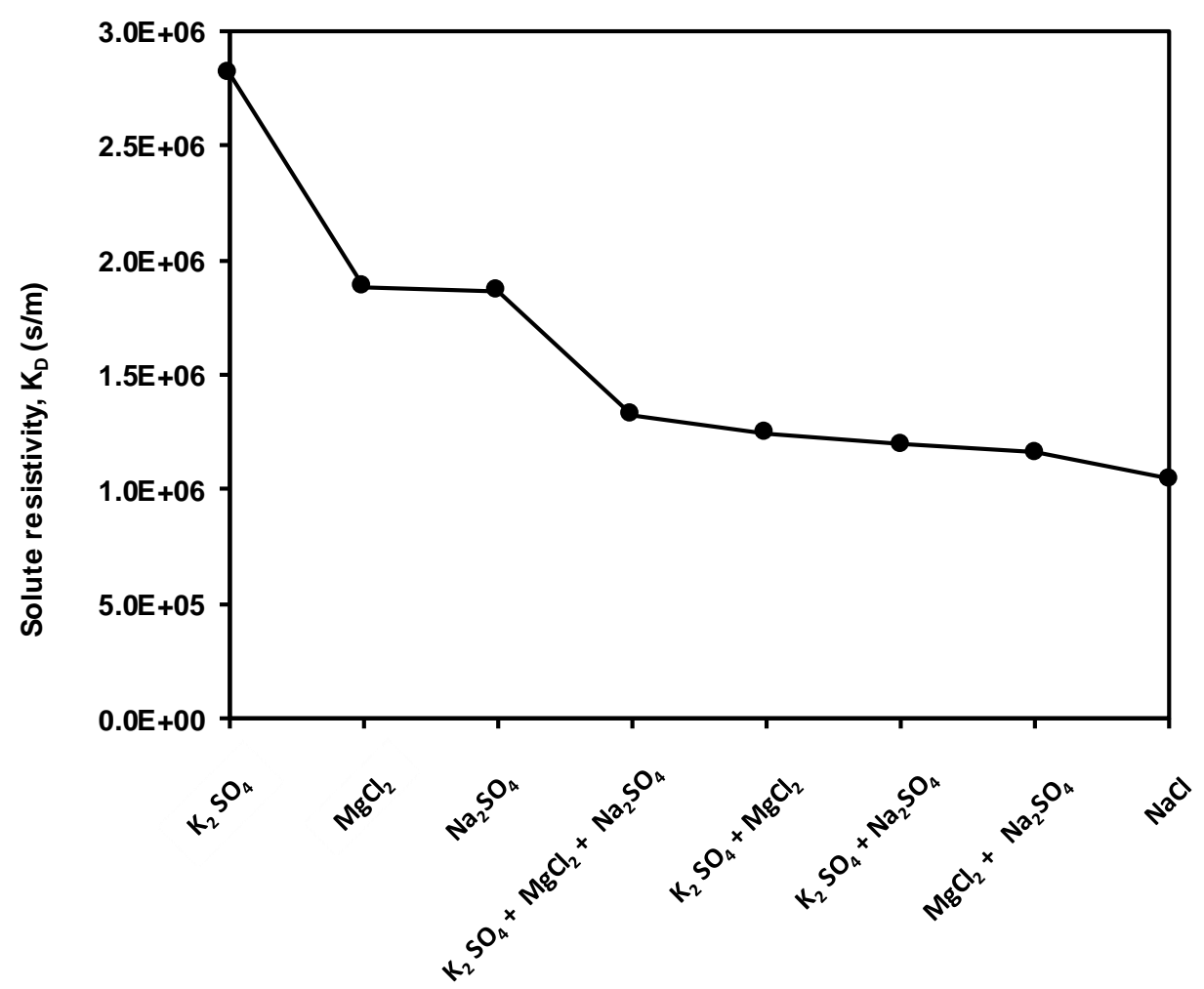

Figure 6 Solute resistivity of a) seawater and $\mathrm{RO}$ at different dilutions b) single and multiple salt solutions that are having same mass concentrations 


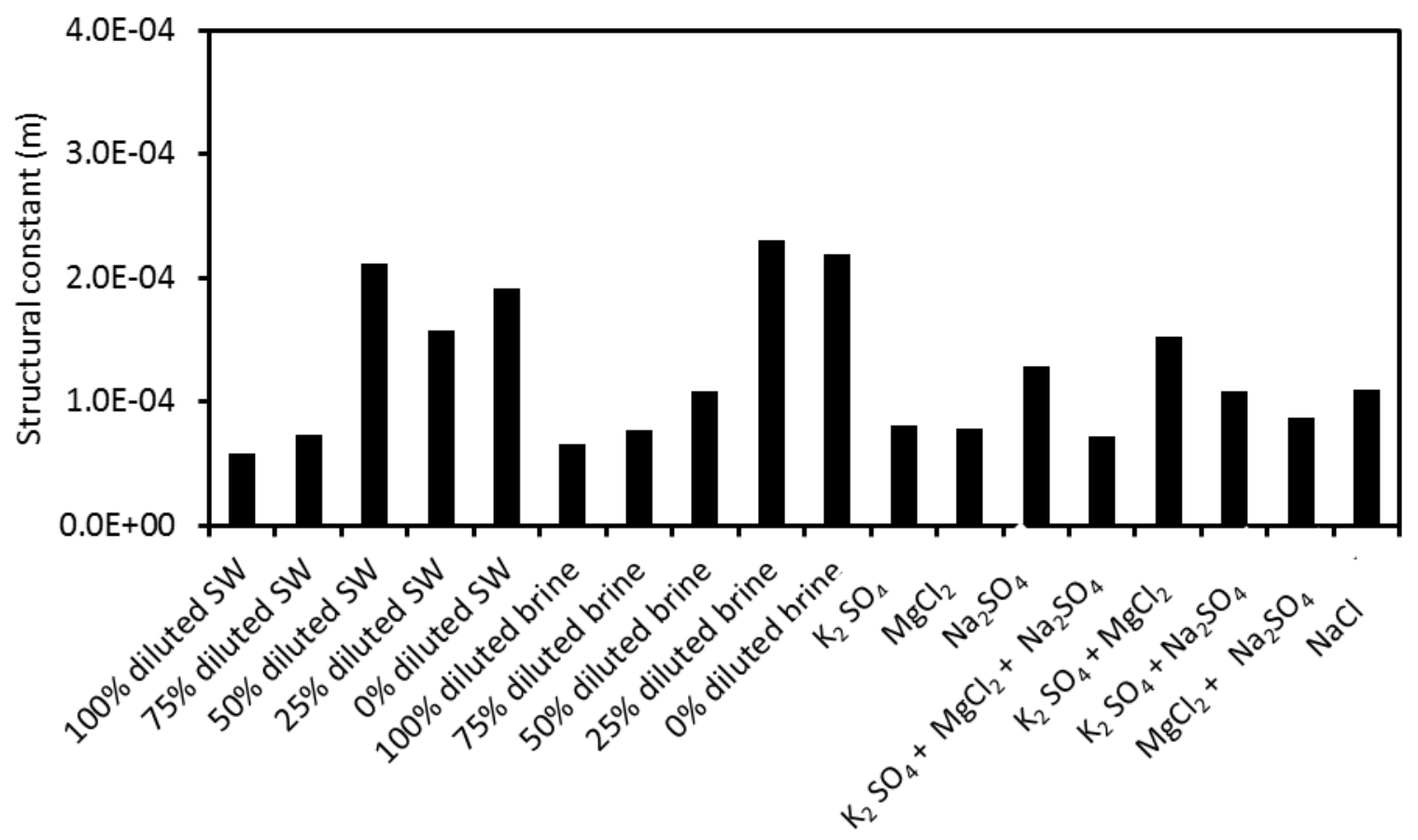

48

Figure $7 \quad$ Structural coefficient of different salt solutions 
51 Table $1 \quad$ Properties of feed and draw solution used in this study

\begin{tabular}{lrrr}
\hline Property & Seawater & $\begin{array}{l}\text { Filtered } \\
\text { seawater }\end{array}$ & $\begin{array}{r}\text { Reverse } \\
\text { osmosis } \\
\text { concentrate }\end{array}$ \\
\hline $\mathrm{pH}$ & 8.42 & 7.68 & 7.77 \\
Turbidity (NTU) & 29.1 & 0.45 & - \\
$\mathrm{EC}(\mathrm{mS} / \mathrm{m})$ & 4,450 & 4,470 & 7,300 \\
TOC $(\mathrm{mg} / \mathrm{L})$ & 1.71 & 0.73 & 3.10 \\
Alkalinity - mg/L as $\mathrm{CaCO} 3$ & 110 & 45 & 68 \\
Hardness (EDTA) - mg/L as $\mathrm{CaCO}_{3}$ & 4,600 & 6,200 & 9,550 \\
\hline
\end{tabular}

52

53 Table 1(b) Ionic composition of seawater and RO concentrate

\begin{tabular}{lrrr}
\hline & & $\begin{array}{l}\text { Seawater } \\
(\mathbf{m g} / \mathrm{L})\end{array}$ & $\begin{array}{l}\text { RO } \\
\text { concentrate } \\
(\mathrm{mg} / \mathrm{L})\end{array}$ \\
\hline Cations & $\mathrm{Ca}^{2+}$ & 457 & 1,101 \\
& $\mathrm{Na}^{+}$ & 8,773 & 19,130 \\
& $\mathrm{Mg}^{2+}$ & 469 & 2,947 \\
& $\mathrm{~K}^{+}$ & 414 & 815 \\
Anions & $\mathrm{Cl}^{-}$ & 22,300 & 18,000 \\
& $\mathrm{SO}_{4}{ }^{2-}$ & 2,200 & 2,200 \\
& $\mathrm{NO}_{3}{ }^{-}$as N & 1.2 & 0.4 \\
\hline
\end{tabular}

54

55

Table 2 Salt solution mixing ratios

\begin{tabular}{|c|c|c|}
\hline Salt solution & $\begin{array}{l}\text { Final concentration } \\
(\mathrm{g} / \mathrm{L})\end{array}$ & Mixing ratio $(\mathrm{g} / \mathrm{L})$ \\
\hline $\mathrm{K}_{2} \mathrm{SO}_{4}$ & 30 & 30 \\
\hline $\mathrm{MgCl}_{2}$ & 30 & 30 \\
\hline $\mathrm{Na}_{2} \mathrm{SO}_{4}$ & 30 & 30 \\
\hline $\mathrm{K}_{2} \mathrm{SO}_{4}+\mathrm{MgCl}_{2}+\mathrm{Na}_{2} \mathrm{SO}_{4}$ & 30 & $7.4+13.5+9.1$ \\
\hline $\mathrm{K}_{2} \mathrm{SO}_{4}+\mathrm{MgCl}_{2}$ & 30 & $10.6+19.4$ \\
\hline $\mathrm{K}_{2} \mathrm{SO}_{4}+\mathrm{Na}_{2} \mathrm{SO}_{4}$ & 30 & $13.5+16.5$ \\
\hline $\mathrm{MgCl}_{2}+\mathrm{Na}_{2} \mathrm{SO}_{4}$ & 30 & $18.0+12.0$ \\
\hline $\mathrm{NaCl}$ & 30 & 30 \\
\hline
\end{tabular}

57 


\begin{tabular}{|c|c|c|c|c|}
\hline Draw solution & $\begin{array}{l}\text { Conductivity, } \\
\text { EC }(\mathrm{mS} / \mathrm{cm})\end{array}$ & $\begin{array}{l}\text { Density, } \rho \\
\left(\mathrm{kg} / \mathrm{m}^{3}\right)\end{array}$ & $\begin{array}{l}\text { Viscosity, } \mu \\
(\text { Pa·s) }\end{array}$ & $\begin{array}{l}\text { Osmotic pressure } \\
\Pi_{D, b} \text { (bar) }\end{array}$ \\
\hline \multicolumn{5}{|l|}{ 1. Seawater } \\
\hline $100 \%$ dilution & 28.55 & 1024.2656 & 0.001027 & 14.27 \\
\hline $75 \%$ dilution & 32.40 & 1024.2656 & 0.001027 & 16.19 \\
\hline $50 \%$ dilution & 37.13 & 1023.6881 & 0.000981 & 18.54 \\
\hline $25 \%$ dilution & 42.60 & 1023.6881 & 0.000981 & 21.32 \\
\hline $0 \%$ dilution & 52.95 & 1023.6881 & 0.000981 & 26.10 \\
\hline \multicolumn{5}{|l|}{ 2. RO concentrate } \\
\hline $100 \%$ dilution & 36.90 & 1024.2656 & 0.001027 & 17.96 \\
\hline $75 \%$ dilution & 43.45 & 1023.9808 & 0.001004 & 20.18 \\
\hline $50 \%$ dilution & 45.75 & 1023.9808 & 0.001004 & 23.27 \\
\hline $25 \%$ dilution & 55.43 & 1024.2656 & 0.001027 & 26.53 \\
\hline $0 \%$ dilution & 67.33 & 1023.9808 & 0.001004 & 33.03 \\
\hline \multicolumn{5}{|l|}{ 3. Salt solution } \\
\hline $\mathrm{K}_{2} \mathrm{SO}_{4}$ & 30.40 & 1023.19 & 0.001266 & 8.53 \\
\hline $\mathrm{MgCl}_{2}$ & 45.70 & 1025.13 & 0.001390 & 22.11 \\
\hline $\mathrm{Na}_{2} \mathrm{SO}_{4}$ & 29.50 & 1026.53 & 0.001335 & 10.25 \\
\hline $\mathrm{K}_{2} \mathrm{SO}_{4}+\mathrm{MgCl}_{2}+\mathrm{Na}_{2} \mathrm{SO}_{4}$ & 34.90 & 1024.29 & 0.001343 & 14.17 \\
\hline $\mathrm{K}_{2} \mathrm{SO}_{4}+\mathrm{MgCl}_{2}$ & 41.60 & 1019.43 & 0.001317 & 12.10 \\
\hline $\mathrm{K}_{2} \mathrm{SO}_{4}+\mathrm{Na}_{2} \mathrm{SO}_{4}$ & 28.80 & 1026.05 & 0.001307 & 8.85 \\
\hline $\mathrm{MgCl}_{2}+\mathrm{Na}_{2} \mathrm{SO}_{4}$ & 38.60 & 1025.26 & 0.001370 & 16.78 \\
\hline $\mathrm{NaCl}$ & 45.70 & 1021.04 & 0.001278 & 22.38 \\
\hline
\end{tabular}

60

61

62

63

64

65

66

67

68

69 
71 Table $4 \quad$ Calculated effective diffusion coefficients and structural constants for each salt solution

\begin{tabular}{|c|c|c|c|c|c|}
\hline Draw solution & $\begin{array}{r}\text { Solute } \\
\text { resistivity, } \\
K_{D}(\mathrm{~s} / \mathrm{m})\end{array}$ & $\begin{array}{r}\text { Mass transfer } \\
\text { coefficient, } \\
k_{d}(\mathrm{~m} / \mathrm{s})\end{array}$ & $\begin{array}{c}\text { Reynolds } \\
\text { number, }\end{array}$ & $\begin{array}{r}\text { Effective } \\
\text { diffusion } \\
\text { coefficient, } \\
D_{\text {eff }}\left(\mathrm{cm}^{2} / \mathrm{s}\right)\end{array}$ & $\begin{array}{r}\text { Structural } \\
\text { coefficient, } \\
K_{D} D_{\text {eff }}(\mathbf{m})\end{array}$ \\
\hline \multicolumn{6}{|l|}{ 1. Seawater } \\
\hline $100 \%$ (dilution) & $7.13 \mathrm{E}+05$ & $2.40 \mathrm{E}-06$ & 1558.4 & $8.15 \mathrm{E}-07$ & $5.81 \mathrm{E}-05$ \\
\hline $75 \%$ (dilution) & $7.63 \mathrm{E}+05$ & 2.69E-06 & 1558.4 & $9.69 \mathrm{E}-07$ & 7.39E-05 \\
\hline $50 \%$ (dilution) & $7.06 \mathrm{E}+05$ & $5.73 \mathrm{E}-06$ & 1630.5 & $3.00 \mathrm{E}-06$ & $2.11 \mathrm{E}-04$ \\
\hline $25 \%$ (dilution) & $6.83 \mathrm{E}+05$ & 4.81E-06 & 1630.5 & $2.31 \mathrm{E}-06$ & $1.57 \mathrm{E}-04$ \\
\hline $0 \%$ (dilution) & $7.03 \mathrm{E}+05$ & $5.38 \mathrm{E}-06$ & 1630.5 & $2.72 \mathrm{E}-06$ & $1.92 \mathrm{E}-04$ \\
\hline \multicolumn{6}{|l|}{ 2. RO concentrate } \\
\hline $100 \%$ (dilution) & $5.68 \mathrm{E}+05$ & 3.05E-06 & 1558.4 & $1.17 \mathrm{E}-06$ & $6.63 \mathrm{E}-05$ \\
\hline $75 \%$ (dilution) & $5.84 \mathrm{E}+05$ & 3.30E-06 & 1593.6 & $1.31 \mathrm{E}-06$ & 7.67E-05 \\
\hline $50 \%$ (dilution) & $5.02 \mathrm{E}+05$ & 4.60E-06 & 1593.6 & $2.16 \mathrm{E}-06$ & $1.08 \mathrm{E}-04$ \\
\hline $25 \%$ (dilution) & $5.56 \mathrm{E}+05$ & 7.14E-06 & 1558.4 & 4.16E-06 & $2.31 \mathrm{E}-04$ \\
\hline $0 \%$ (dilution) & $5.04 \mathrm{E}+05$ & 7.37E-06 & 1593.6 & $4.36 \mathrm{E}-06$ & $2.20 \mathrm{E}-04$ \\
\hline \multicolumn{6}{|l|}{ 3. Salt solution } \\
\hline $\mathrm{K}_{2} \mathrm{SO}_{4}$ & $1.87 \mathrm{E}+06$ & $1.31 \mathrm{E}-06$ & 324.8 & $4.30 \mathrm{E}-07$ & 8.03E-05 \\
\hline $\mathrm{MgCl}_{2}$ & $1.20 \mathrm{E}+06$ & $1.73 \mathrm{E}-06$ & 296.3 & $6.54 \mathrm{E}-07$ & 7.83E-05 \\
\hline $\mathrm{Na}_{2} \mathrm{SO}_{4}$ & $1.88 \mathrm{E}+06$ & $1.79 \mathrm{E}-06$ & 309.1 & $6.84 \mathrm{E}-07$ & $1.29 \mathrm{E}-04$ \\
\hline $\mathrm{K}_{2} \mathrm{SO}_{4}+\mathrm{MgCl}_{2}+\mathrm{Na}_{2} \mathrm{SO}_{4}$ & $1.25 \mathrm{E}+06$ & $1.59 \mathrm{E}-06$ & 306.6 & $5.73 \mathrm{E}-07$ & 7.15E-05 \\
\hline $\mathrm{K}_{2} \mathrm{SO}_{4}+\mathrm{MgCl}_{2}$ & $1.05 \mathrm{E}+06$ & $2.97 \mathrm{E}-06$ & 311.2 & $1.46 \mathrm{E}-06$ & $1.53 \mathrm{E}-04$ \\
\hline $\mathrm{K}_{2} \mathrm{SO}_{4}+\mathrm{Na}_{2} \mathrm{SO}_{4}$ & $2.82 \mathrm{E}+06$ & $1.22 \mathrm{E}-06$ & 315.6 & $3.86 \mathrm{E}-07$ & $1.09 \mathrm{E}-04$ \\
\hline $\mathrm{MgCl}_{2}+\mathrm{Na}_{2} \mathrm{SO}_{4}$ & $1.16 \mathrm{E}+06$ & $1.91 \mathrm{E}-06$ & 300.8 & 7.54E-07 & $8.74 \mathrm{E}-05$ \\
\hline $\mathrm{NaCl}$ & $1.33 \mathrm{E}+06$ & $2.04 \mathrm{E}-06$ & 321.0 & 8.32E-07 & $1.10 \mathrm{E}-04$ \\
\hline
\end{tabular}

